\title{
Robotic and Sensor Technologies for Mobility in Older People
}

\author{
Lazaros Penteridis, Grazia D'Onofrio,,3 Daniele Sancarlo,2 Francesco Giuliani, \\ Francesco Ricciardi, Filippo Cavallo, Antonio Greco, ${ }^{3}$ lias Trochidis, ${ }^{1}$ and Alexander Gkiokas ${ }^{1}$
}

\begin{abstract}
Maintaining independent mobility is fundamental to independent living and to the quality of life of older people. Robotic and sensor technologies may offer a lot of potential and can make a significant difference in the lives of older people and to their primary caregivers. The aim of this study was to provide a presentation of the methods that are used up till now for analysis and evaluation of human mobility utilizing sensor technologies and to give the state of the art in robotic platforms for supporting older people with mobility limitations. The literature was reviewed and systematic reviews of cohort studies and other authoritative reports were identified. The selection criteria included (1) patients with age $\geq 60$ years; (2) patients with unstable gait, with or without recurrent falls; (3) patients with slow movements, short strides, and little trunk movement; (4) sensor technologies that are currently used for mobility evaluation; and (5) robotic technologies that can serve as a supporting companion for older people with mobility limitations. One hundred eighty-one studies published up until February 2017 were identified, of which 36 were included. Two categories of research were identified from the review regarding the robot and sensor technologies: (1) sensor technologies for mobility analysis and (2) robots for supporting older people with mobility limitations. Potential for robotic and sensor technologies can be taken advantage of for evaluation and support at home for elder persons with mobility limitations in an automated way without the need of the physical presence of any medical personnel, reducing the stress of caregivers.
\end{abstract}

Keywords: older people, mobility limitation, sensor technologies, robotic technologies

\section{Introduction}

$\mathbf{P}$ OPULATION AGING is associated with an increase in the number of people who are disabled. ${ }^{1}$ The major burdens of disability and death arise from age-related losses in hearing, seeing, and moving, and noncommunicable diseases, including heart disease, stroke, chronic respiratory disorders, cancer, and dementia, such as declines in physical, emotional, and cognitive capacity, and difficulties with vision, balance, and mobility. ${ }^{2}$

Difficulties in mobility are often the first sign of functional decline $^{3}$ and their incidence is $\sim 35 \%$ of adults aged over 70 years and $72 \%$ of people aged over 80 years. ${ }^{4,5}$ Mobility limitations are associated with loss of autonomy, reduced quality of life, increased fall risk, repeated hospitalizations, and premature death. ${ }^{6}$ Furthermore, longitudinal predictors of mobility decline were shown and included increasing age, ${ }^{7}$ reduced leg strength, ${ }^{8-10}$ obesity, ${ }^{11}$ poor self-rated health, number of morbidities, and psychosocial factors. ${ }^{12}$

Walking is the fundamental mobility task for human life and is a complex neuromotor activity. ${ }^{13}$ Moreover, with advancing age, maintaining mobility and walking capability may be made vulnerable by the increasing risk of physical and sensory impairments. ${ }^{14}$ It was shown that persons walking slower than $1 \mathrm{~m} / \mathrm{s}$ are likely to be limited in energy needed for self-care, and persons walking faster than $1 \mathrm{~m} / \mathrm{s}$ may be expected to have the capacity to perform household activities. ${ }^{15}$ Mobility is widely measured through selfreports such as the ability to walk $400 \mathrm{~m} .^{10,16-18}$

Maintaining independent mobility is fundamental to independent living and to the quality of life of older people. ${ }^{19}$

\footnotetext{
${ }^{1}$ Ortelio Ltd., Coventry University Technology Park, Puma Way, Coventry, United Kingdom.

${ }^{2}$ Complex Unit of Geriatrics, Department of Medical Sciences, IRCCS "Casa Sollievo della Sofferenza," San Giovanni Rotondo, Foggia, Italy.

${ }^{3}$ The BioRobotics Institute, Scuola Superiore Sant'Anna, Pontedera, Italy.

${ }^{4}$ ICT, Innovation \& Research Unit, IRCCS "Casa Sollievo della Sofferenza," San Giovanni Rotondo, Foggia, Italy.
} 
Robotic and sensor technologies may offer a lot of potential and can make a significant difference in the lives of older people and to their primary caregivers. Indeed, it has been noted that these technologies should be part of a home package and should be provided in a thoughtful, sensitive, and ethical way. ${ }^{20}$

The objectives of this article were to provide a presentation of the methods that are used up till now for analysis and evaluation of human mobility utilizing sensor technologies and to give the state of the art in robotic platforms for supporting older people with mobility limitations.

\section{Methods}

The PRISMA guidelines for this systematic review were followed. ${ }^{21}$ PubMed, Embase, CINAHL, ScienceDirect, and Scopus were searched up until February 2017.

The search queries included the following terms (Robotic technologies OR Robotics AND Sensor technologies OR Sensors AND older OR elderly) combined with terms to determine the outcomes of interest (mobility AND [disability OR decline OR disorders] OR Walking OR Gait) and were limited to human studies.

A single reviewer examined the abstracts retrieved by the electronic search to identify articles that met the inclusion criteria and have to be fully reviewed.

The inclusion criteria included research articles inclusive of (1) patients with age $\geq 60$ years; (2) patients with unstable gait, with or without recurrent falls; (3) patients with slow movements, short strides, and little trunk movement according to the description given by Snijders et al. ${ }^{22}$; (4) sensor technologies that are currently used for mobility evaluation; and (5) robotic technologies that can serve as supporting companion for older people with mobility limitations. Exclusion criteria were (1) no English language (as we lacked resources for translation) and (2) no mobility limitations.

As shown in Figure 1, a total of 181 articles were identified, of which 65 duplicates were deleted. After reviewing abstracts, 70 articles were excluded on the basis of the aforementioned exclusion criteria. Further 10 articles were excluded after more in-depth examination (on the basis of the same inclusion/exclusion criteria). Thus, 36 published studies were eligible for the current systematic review as shown in Tables 1 and 2.

An inductive approach to the analysis was used. ${ }^{23}$ The Results section was divided in two categories:

(1) Sensor technologies for mobility analysis

(2) Robots for supporting older people with mobility limitations.

Coauthors provided a detailed summary of each study, including its strengths and weaknesses, as well as an overall review of the category. ${ }^{24,25}$ Through this process, the following items were systematically extracted from the articles: approach, methodology, transparency, strengths, and weaknesses. Then, these were organized according to theme to provide an overview of the state of the field as a whole.

\section{Results}

\section{Sensor technologies for mobility analysis}

The potential sensor technologies that assess the mobility of older people are shown in Table 1.

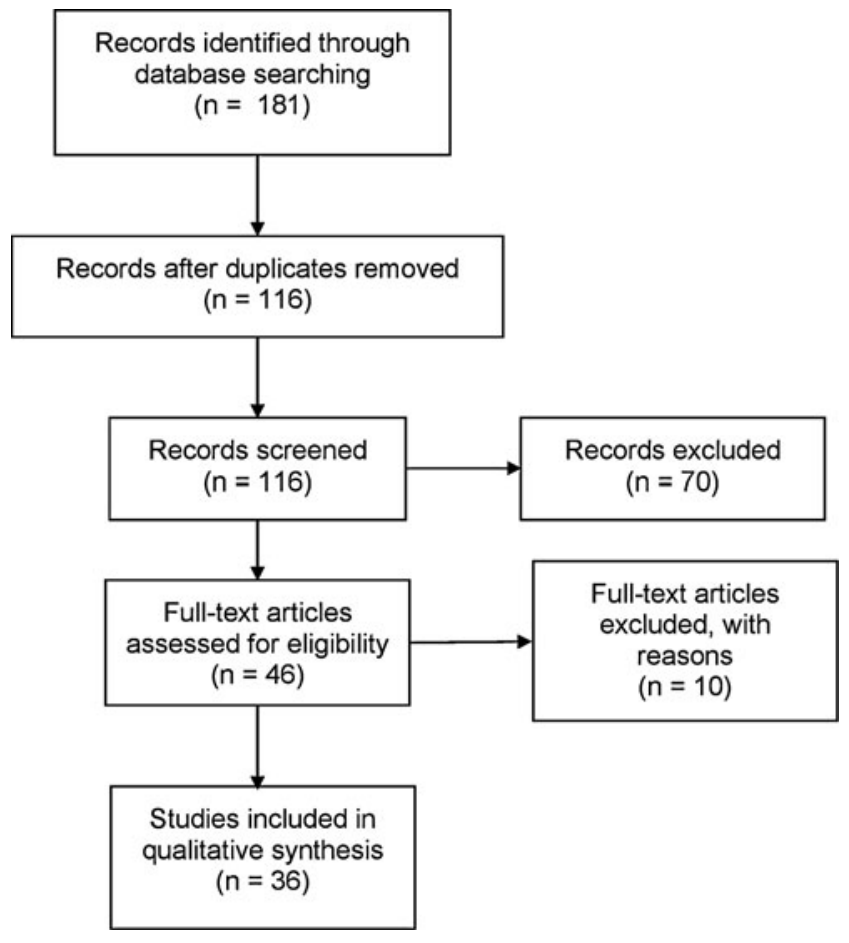

FIG. 1. Flow diagram outlining the selection procedure to identify articles that were included in the state of the art sensor technologies for mobility analysis and robotic platforms for supporting older people with mobility limitations.

The methods used in recognition and analysis of human mobility follow three different approaches: image processing (IP), floor sensors (FS), and sensors placed on the body. Progress in new technologies has led to the development of a series of devices and techniques, which allow for objective evaluation, making measurements more efficient and effective and providing specialists with reliable information.

The technological devices used to study human mobility can be classified according to two different approaches: those based on nonwearable sensors (NWSs) and on wearable sensors (WSs). There is also a third group of hybrid systems that use a combination of both methods. ${ }^{26,27}$ NWS systems can be classified into two subgroups: (1) IP and (2) FS. IP systems capture data on the subject's gait through one or more optic sensors and take objective measurements of the different parameters through digital IP. ${ }^{28}$ Analog or digital cameras are the most commonly used devices. Other types of optic sensors such as laser range scanners, infrared sensors, and time-of-flight cameras are also used. There are two systems within this category: with and without markers. The FS systems are based on sensors located along the floor on the so-called force platforms where gait information is measured through pressure sensors and ground reaction force sensors, which measure the force exerted by the subject's feet on the floor when he/she walks.

The WS systems use sensors located on several parts of the body, such as feet, knees, thighs, or waist. Different types of sensors are used to capture various signals that characterize the human gait. These include accelerometers, gyroscopic sensors, magnetometers, force sensors, extensometers, goniometers, active markers, and electromyography, etc. 
Table 1. Sensor Technologies for Mobility in Older People

\begin{tabular}{|c|c|c|c|c|}
\hline Studies & References & Methods & Application & Outcomes \\
\hline Cho et al. & 33 & $\mathrm{PCA}+\mathrm{LDA}$ & Image & $\begin{array}{l}\text { The proposed system is a promising aid in identifying } \\
\text { the gait of PD patients and can discriminate the gai } \\
\text { patterns of PD patients and normal people with a } \\
\text { very high classification rate. }\end{array}$ \\
\hline $\begin{array}{l}\text { Zeng and } \\
\text { Zhao }\end{array}$ & 30 & MS & $\begin{array}{l}\text { Image, accelerometer, } \\
\text { and gyroscope }\end{array}$ & $\begin{array}{l}\text { With their lower cost and increased intelligence, } \\
\text { man-made motion sensors are expected to play an } \\
\text { increasingly important role in biomedical systems } \\
\text { for basic research as well as clinical diagnostics. }\end{array}$ \\
\hline Tao et al. & 27 & $\mathrm{GA}+\mathrm{WS}$ & $\begin{array}{l}\text { Accelerometer, } \\
\text { gyroscope, } \\
\text { magnetometer, } \\
\text { goniometer, ETS, } \\
\text { and EMG }\end{array}$ & $\begin{array}{l}\text { With the development of sensor technology and the } \\
\text { analysis method, gait analysis using WS is } \\
\text { expected to play an increasingly important role } \\
\text { in clinical applications. }\end{array}$ \\
\hline Ganea et al. & 31 & $\mathrm{AM}+\mathrm{PT}$ & $\begin{array}{l}\text { Accelerometer, } \\
\text { gyroscope, } \\
\text { magnetometer, and } \\
\text { barometric pressure }\end{array}$ & $\begin{array}{l}\text { The proposed wearable system provides a simple } \\
\text { method to detect and characterize postural } \\
\text { transitions in healthy, chronic pain, and frail } \\
\text { elderly subjects. }\end{array}$ \\
\hline Wang et al. & 32 & $\begin{array}{l}\text { TASS+RSAU } \\
\quad+3 \mathrm{Ds}\end{array}$ & Image & $\begin{array}{l}\text { TASS effective method decouples the complex } \\
\text { spatiotemporal information of multiple Skeletal } \\
\text { Action, experimental results from people with } \\
\text { PD and people without PD demonstrate. }\end{array}$ \\
\hline Kashani et al. & 34 & PoCM & Image & $\begin{array}{l}\text { PoCM uses both 3D visual sensors (such as } \\
\text { Microsoft Kinect) and mobile sensors } \\
\text { (i.e., internal and external sensors embedded } \\
\text { with/connected to a mobile device such as a } \\
\text { smartphone) for complementary data acquisition, } \\
\text { as well as a series of analytics that allow } \\
\text { evaluation of both archived and real-time } \\
\text { mobility data. }\end{array}$ \\
\hline $\begin{array}{l}\text { Muro-de-la- } \\
\text { Herran et al. }\end{array}$ & 26 & $\mathrm{GA}+\mathrm{ST}+\mathrm{CA}$ & Image & $\begin{array}{l}\text { Various parameters such as precision, conformability, } \\
\text { usability, or transportability have indicated that } \\
\text { the portable systems based on body sensors are } \\
\text { promising methods for gait analysis. }\end{array}$ \\
\hline Geraedts et al. & 29 & NWS+UO & $\begin{array}{l}\text { Accelerometer and } \\
\text { barometric pressure }\end{array}$ & $\begin{array}{l}\text { The necklace-worn sensor is considered an } \\
\text { acceptable valid instrument for assessing home- } \\
\text { based physical activity based upon time-on-legs } \\
\text { in frail and nonfrail older adults, but category- } \\
\text { based assessment of gait and postures could } \\
\text { be further developed. }\end{array}$ \\
\hline
\end{tabular}

3Ds, 3D sensor; AM, ambulatory monitoring; CA, clinical application; EMG, electromyography; ETS, electromagnetic tracking system; GA, gait analysis; HAR, home assistant robot; LDA, linear discrimination analysis; MS, motion sensors; NWS, necklace wearable sensor; PCA, principal component analysis; PD, Parkinson's disease; PoCM, point-of-care mobility monitoring; PT, postural transitions; RSAU, representative skeletal action unit; ST, sensor technology; TASS, temporal alignment spatial summarization; UO, user opinion; WS, wearable sensors.

Several studies are related to the use of WS systems for human mobility detection and analysis while studies refer to the case where optic NWSs are used for that same purpose. ${ }^{29-34}$

In a study, a miniature hybrid sensor is used, which contains a 3D-MEMS accelerometer and a barometric pressure sensor, and is worn as a necklace by the elder person. ${ }^{35}$ After passing the sensor signals though a low pass filter, the smoothed signals are fed to each of the movement and posture detection modules to detect activities such as (1) active period, (2) sit/stand transfer, (3) walking, and (4) lying.

On the other study,${ }^{34}$ the problem of automated quantitative evaluation of musculoskeletal disorders using a 3D optic sensor is addressed. This enables a noninvasive home monitoring system that extracts and analyzes the subject's motion symptoms and provides clinical feedback. In this research, the 3D sensing technology used was the Microsoft Kinect RGB-D sensor. Furthermore, spatiotemporal analysis of noisy, high-dimensional time series data was performed. The general pipeline of this method includes the following steps:

Extract the high-dimensional skeleton data from the Kinect depth video stream.

Temporal segmentation of time series data based on the intrinsic periodicity.

Temporal alignment of all segmented time series sequences. Spatial summarization to generate the final consistent representation.

\section{Robots for supporting older people} with mobility limitations

According to the previous sections, any robot that could somehow encapsulate one or more of the aforementioned sensor technologies could be used for evaluation of the mobility of a human subject, although some of those technologies 
Table 2. Robotic Technologies to Support the Mobility in Older People

\begin{tabular}{|c|c|c|c|}
\hline Robot type & Robot name & References & Developer \\
\hline \multirow{4}{*}{$\begin{array}{l}\text { Humanoid } \\
\text { robots }\end{array}$} & Partner Robots & 40 & Toyota \\
\hline & Bandit-II & 41 & $\begin{array}{l}\text { Interaction Laboratory of } \\
\text { the University of } \\
\text { Southern California }\end{array}$ \\
\hline & NAO & 43 & Aldebaran robotics \\
\hline & Nimbro-OP & 44 & $\begin{array}{l}\text { Institute for Computer } \\
\text { Science of University } \\
\text { of Bonn }\end{array}$ \\
\hline \multirow[t]{2}{*}{ Exoskeletons } & Superflex & 47 & SRI International \\
\hline & HAL & 48,49 & Cyberdyne, Inc. \\
\hline $\begin{array}{l}\text { Tool-like } \\
\text { robot }\end{array}$ & PAW & 50 & $\begin{array}{l}\text { Clinton River Medical } \\
\text { Products }\end{array}$ \\
\hline $\begin{array}{l}\text { Rehabilitation } \\
\text { robot }\end{array}$ & $\begin{array}{l}\text { Walking-aid } \\
\text { robot }\end{array}$ & 51,52 & ETH Zurich \\
\hline
\end{tabular}

\section{Service \\ robots}

Amigo $48 \quad \begin{gathered}\text { Eindhoven University of } \\ \text { Technology }\end{gathered}$
Ang

ASTROmobile

49

Care-o-bot
Fraunhofer Institute for Manufacturing Engineering and Automation
Intelligent multisensor control (harmonious control). Timing lock mechanism.

Can pan and tilt its head. Stereo cameras as its eyes. Movable mouth and eyebrows that allow a variety of friendly facial expressions. Pair of arms with six times degrees of freedom. Stands on a wheel-driven platform that allows moving to all directions, easy.

Multilingual personalizable robot with interactive qualities. Designed to encourage in a positive and impassive manner. Designed to reproduce human behavior. Can be individualized to be proficient in specific skills and carry out certain tasks and behaviors. It has sensors at head, hands, and feet to enable recording of new areas. Unit is equipped with technology to determine whether it is upright or horizontal (useful in case of falls).

Modular, open-source humanoid robot for research and education. ROS-based software.

Motion sensors, accelerometers, and gyroscopes to read the speed and angles of the owner's legs and adjust its movements accordingly.

Control system consists of two different modes: cybernic voluntary control (based on a user's muscle signals) and cybernic autonomous control (for individuals with severe impairments).

More control when navigating hills and uneven surfaces or various terrains and can travel longer distances with less fatigue.

$3 \mathrm{D}$ camera that can swivel $360^{\circ}$ to probe the environment and measure the distance between the user and the walker. A laser sensor constantly measures the distance from the user's legs and monitors the ground to detect obstacles. Another sensor measures the walker's inclination. The walker is controlled through a simple user interface. It responds to users' gestures and rolls over to them without any outside assistance.

Tech United's care robot. With a height of one and a half meters, the robot is equipped with two arms and a wheel-based platform. While AMIGO uses its special wheels to easily move around the house, it performs human tasks such as grasping objects and opening cupboards with its arms.

The functional layer includes algorithms with decision-making and cognitive reasoning capabilities. Action and emotion recognition, navigation with obstacle avoidance, selecting the appropriate information to display, or establishing communication.

Range of caring and socially interacting robot with an adaptable personality. It has a visual display that can depict various atmospheres, and the entire model has a more caring and personal feel about it. 
Table 2. (Continued)

\begin{tabular}{|c|c|c|c|}
\hline Robot type & Robot name & References & Developer \\
\hline & Enon & 51 & Fujitsu \\
\hline & Carebot & 52 & GeckoSystems Intl. Corp. \\
\hline & HSR & 53 & Toyota \\
\hline & IRT & 54 & $\begin{array}{l}\text { Department of Mechano- } \\
\text { Informatics of the } \\
\text { University of Tokyo }\end{array}$ \\
\hline & REEM H1 & 55 & Pal robotics \\
\hline & PR2 & 56 & Willow Garage \\
\hline & SMARTPAL V & 57 & Yaskawa \\
\hline
\end{tabular}

$\begin{array}{cccc}\text { Twenty One } & 58 & \text { Waseda University } \\ & \begin{array}{c}\text { UFES Smart } \\ \text { Walker }\end{array} & 66 & \begin{array}{c}\text { Federal University of } \\ \text { Espirito Santo }\end{array} \\ \text { APR } & 67 & \begin{array}{c}\text { Universitat de Lleida, } \\ \text { Spain }\end{array} \\ \begin{array}{c}\text { Companion- } \\ \text { type } \\ \text { robots-pets }\end{array} & \text { PARO } & 68 & \begin{array}{c}\text { Intelligent System } \\ \text { Research Institute } \\ \text { of Japan's AIST }\end{array}\end{array}$

High-resolution camera allows thorough monitoring and patrolling. Built-in Map Localization Software for efficient navigation. Onboard obstacle sensors for safe place-toplace movement. LEDs placed in its eyes and mouth, which enable expression of a variety of expressions. With good pair of hands capable of grasping and holding things.

Provides CyberMobility to patients. Obstacle avoidance through Microsoft Kinect. Object recognition. Multiple sensor systems. Artificial intelligence system (GeckoSavant). Equipped with video camera. Speech synthesis.

Folding arm. Flexible hand. Object recognition and grasp planning. Environment recognition and autonomous mobility. Remote functions.

Ability to imitate human movements. Installed with a pair of network device for upper and lower body maneuvering. Equipped with motion capture technology

It has a touchscreen LCD and is capable of recognizing people by face recognition and face tracking technology. REEM-H1 makes use of its autonomous navigation system to walk around indoor spaces and uses microphones to detect multilingual speed.

It is capable of opening doors and can identify an electrical outlet to recharge. Moreover, the robot can fold towels, play music, pick up trash, fetch beer, autonomously recharge itself, and play the game of pool.

The robot moves freely on its wheeled base; it can distinguish one person's voice out of a crowd and obey its owner's instructions. It also offers voice synthesis capabilities to respond directly to questions. SmartPal V's ability to recognize its environment is provided by its cameras and special software; it can also be taught particular objects that belong to you so that it can take care of them better.

It can manipulate an object dexterously as well as support a human.

User-machine multimodal interaction for obtaining a natural control strategy for the robotic device.

The APR uses a tablet and features a fast highmobility motion system adapted for teleoperation in plain indoor areas, which incorporates a high-priority collision avoidance procedure.

It has five kinds of sensors: tactile, light, audition, temperature, and posture sensors, with which it can perceive people and its environment. With the light sensor, PARO can recognize light and dark. He feels being stroked and beaten by tactile sensor or being held by the posture sensor. PARO can also recognize the direction of voice and words such as its name, greetings, and praise with its audio sensor. 
TABle 2. (CONTINUED)

\begin{tabular}{|c|c|c|c|c|}
\hline Robot type & Robot name & References & Developer & Functions \\
\hline & PLEO & 69 & Innvo Labs & $\begin{array}{l}\text { Built-in cameras for topnotch navigation and } \\
\text { light detection. Dual microphone. A total of } \\
\text { eight touch sensors are cleverly mounted on } \\
\text { the head, chin, shoulders, back, and feet. } \\
\text { Fourteen state-of-the-art force-feedback sen- } \\
\text { sors are incorporated on each joint for more } \\
\text { efficient motion. } \\
\text { Supercool beat detection sensor is included } \\
\text { on the robot, allowing PLEO to detect beats } \\
\text { and dance to them. Surface detection sensor } \\
\text { integrated on each foot. Tilt sensor for } \\
\text { position determination. Infrared sensor is } \\
\text { placed inside the mouth for object detection. } \\
\text { Capable of communicating with other PLEOs } \\
\text { using two-way infrared. } \\
\text { Online downloads made possible using its } \\
\text { mini-USB port. PLEO robot add-ons avail- } \\
\text { able through its SD card slot. Uses a 32-bit } \\
\text { Atmel ARM7 microprocessor as a main } \\
\text { processor. }\end{array}$ \\
\hline & BUDDY & 70 & Blue Frog Robotics & $\begin{array}{l}\text { Communication, interactions, and emotional } \\
\text { responses. }\end{array}$ \\
\hline & PaPeRo Petit & 71 & $\mathrm{NEC}$ & $\begin{array}{l}\text { It uses different technologies to interact with its } \\
\text { environment, has a speech recognition sys- } \\
\text { tem, uses an ultrasound system located in its } \\
\text { chest to detect objects, and has other sensors } \\
\text { located in its head, which can detect if the } \\
\text { robot is patted and slapped. }\end{array}$ \\
\hline & iCat & 72 & $\begin{array}{l}\text { Philips Research } \\
\text { Europe }\end{array}$ & $\begin{array}{l}\text { Built-in webcam in its eyes. Object and face } \\
\text { recognition. Stereo soundcard. Speakers and } \\
\text { stereo microphones. OPPR software. Limb- } \\
\text { less. }\end{array}$ \\
\hline
\end{tabular}

APR, assistant personal robot; ARM7, advanced RISC machines 7; HAL, hybrid assistive limb; HSR, human support robot; IRT, information and robot technology; LED, light-emitting diode; LCD, liquid crystal display; OPPR, open platform for personal robotics; PAW, power-assisted wheelchair; ROS, robot operating system.

are impossible to implement on a robotic technology, such as WS and FS. Therefore, we were focused here on robotic platforms that belong to the category of assistive robots to support older people with mobility limitations and at risk of exclusion ${ }^{36}$ and of course have the necessary sensors for mobility evaluation (optic in these cases). We divided this wide category of robots to the following subcategories: 4 humanoid robots, 2 exoskeletons, 1 tool-like robot, 1 rehabilitation robot, 13 service robots, and 5 companion-type robots-pets (Table 2).

Humanoid robots. The main characteristic of humanoid robots is anthropomorphism and high mobility, with some of them being able to perform a variety of physical movements and most of them act as companions too. They not only belong to the wider category of social robots but could also fit in the companion-type category too. ${ }^{37}$ Nowadays, humanoid robots are used as a research tool in several scientific areas. Although anthropomorphic features should be carefully designed, ${ }^{38}$ anthropomorphism itself is considered a useful attribute in inclusion and interactive sessions as it facilitates easier interactions and better communication. ${ }^{39}$

There is evidence that some advanced humanoid robots such as Partner Robots and the Bandit-II have been used to support the elderly care. ${ }^{40,41}$
These are research robots that are expensive, not yet commercially available, and their development is still in progress. They all use Linux-based operating systems and most of them are compatible with Robot Operating System (ROS). Due to their characteristics as humanoid robots, they could be used to support the elderly and people at risk of exclusion.

Finally, there exist some humanoid robots such as NAO and Nimbro-OP. These are financially affordable and commercially available (from $7.000 €$ to $22.000 €$ ) anthropomorphic robots that are used mainly for research purposes. They are around $45-80 \mathrm{~cm}$ tall and weigh from 3 to $5 \mathrm{~kg}$. They all use Linux-based operating system and are compatible with ROS. NAO has already been used to support autistic children ${ }^{42}$ and has been used in an assistive living environment to support the elderly. ${ }^{43}$ There is also recent study $^{44}$ that claims Nimbro-OP has been used as a companion robot to support the elderly. They all have optic sensors, so theoretically they can be used for human mobility and gait evaluation with the right software.

Exoskeletons. Several powered exoskeletons are currently available and in clinical use. Some evidence exists to support their utility for rehabilitation in stroke and other acquired brain injuries. ${ }^{45}$ The current systems have many 
limitations and a myriad of differences exist in their engineering concept, design, control mechanism, and performance. Assistance of the exoskeleton is perceived to reduce less muscle fatigue compared with normal walking. ${ }^{46}$ Studied exoskeletons for older people with reduced mobility are the following: Superflex ${ }^{47}$ and Hybrid Assistive Limb (HAL). ${ }^{48}$ Rather than imagining the humanoid robot as a plastic person that has two arms and two legs, the exoskeletons, as Superflex, propose that the robot could be built into everyday garments. Superflex's elastic muscle technology provides for the combination of a wetsuit and kinesio-tape. The suit's sensors are supposed to be able to track the posture and movement of the body, and rapidly process data to send a motor assist when the wearer is leaning forward in a chair, getting ready to stand up, or even starting to raise their arms above their head.

Regarding the HAL, studies have evaluated the ability of this exoskeleton to provide task-specific locomotor training in individuals poststroke as well as a clinical device to be used in therapy sessions for persons with limited mobility from stroke or other musculoskeletal diseases. ${ }^{48,49}$ In these studies, data indicated that the HAL is capable of improving subjects' walking ${ }^{49}$ and torso posture, as well as enhancing treadmill training, based on $10 \mathrm{~m}$ and 6-minute walk tests, lower extremity motor scores, and the timed up and go test. $^{48}$ The HAL was also reported safe when used alongside an inpatient rehabilitation program. ${ }^{49}$

Exoskeletons appear to be a step in the right direction to allow patients to walk in various environments, on different surfaces, and in some cases under their own control (i.e., patient-controlled gait triggering). ${ }^{45}$

Tool-like robot. Among the tool-like robots for human mobility, only the power-assisted wheelchair (PAW) is suitable for older people. Wheelchairs that have enhanced locomotion of people with muscular weakness or paralysis still can be improved using various assistive technologies, for example, electric wheelchairs have been developed and widely used for enhancement of the maneuverability and safety of people. The PAW ${ }^{50}$ is a relatively new type of wheelchair, which is equipped with torsion sensors to measure force applied on rims by a human and provides the assistive torque based on the measured force. With this propelling process, the user still can involve with the propulsion of the wheelchair, while the assistive torque can relieve the user's propulsion effort. This PAW is a case of human-machine interface and requires an adequate control of assistive torques to interact with a human without confliction. ${ }^{50}$

Rehabilitation robot. To regain normal mobility function as much as possible, gait rehabilitation such as locomotion training is commonly employed as therapy. In this view, the walking-aid robot is significantly useful. ${ }^{51}$ It is an assistive device for enabling safe, stable, and efficient locomotion in elderly people. A study proposed a reinforcement learningbased shared control algorithm for intelligent walking-aid robot to address existing control problems in cooperative walking-aid robot system. ${ }^{52}$ By dynamically adjusting user control weight according to different user control efficiencies and walking environments, the robot can improve the user's degree of comfort when using the device and automatically adapt to user's behavior.

Service robots. A service robot is a robot that performs useful tasks for humans or equipment excluding industrial automation application. ${ }^{53}$ There exists a plethora of service robots, some actively used in research and some employed in environments where their utilization targets are hotels, hospitals, geriatric centers, or even homes. ${ }^{54,55}$ Amigo, ${ }^{56}$ ASTROmobile, ${ }^{57}$ Care-o-bot, ${ }^{58}$ Enon, ${ }^{59}$ Carebot, ${ }^{60}$ Human Support Robot (HSR), ${ }^{61}$ IRT $^{55}$ home assistant, REEM H1, ${ }^{62}$ PR2, ${ }^{63}$ SmartPal V, ${ }^{64}$ Twenty One, ${ }^{65}$ UFES Smart Walker, ${ }^{66}$ and Assistant Personal Robot (APR) ${ }^{67}$ are all service robots used to support older people. While their use could see various different employment scenarios, their main purpose revolves around servicing human users, disabled or not. Some of those are commercially available, some are not, some are financially affordable (e.g., Carebot), and some are prohibitively expensive (e.g., PR2, Care-o-bot).

Due to their nature and their role, service robots could potentially see some benefits in inclusion as they can offer both a supportive role for physical needs and cognitively and educationally challenge their user or users. Where they lack in mobility (due to using tracks or a platform with wheels rather than legs as most humanoids do), they make up with their wide range of operations, long battery life, computational power, and long research history. Technically, most of the service robots mentioned above operate on a Linux operating system and are compatible with ROS. They all have optic sensors, so theoretically they can be used for human mobility and gait evaluation with the right software.

Companion-type robots: pets. A different type of robot, therapeutic pet and social assistant in some form or another, aims to provide companionship and assist their user. Most are normally simulated animals and their assistance is emotional or cognitive to their user rather than physical (in which case, please refer to service robotics). Such robots are Paro ${ }^{68}$ Pleo, ${ }^{69}$ Buddy, ${ }^{70}$ PaPeRo Petit, ${ }^{71}$ and $\mathrm{iCat}^{72}$ and can be used for inclusion purposes. They mostly rely on communication, interactions, and emotional responses from their user. However, their embodiment is usually restricted due to being represented as animals or pets. These robots are usually cheaper. They all have optic sensors (cameras), so theoretically they can be used for human mobility and gait evaluation with the right software. Finally, there are evidences that they can improve the quality of life of the elderly. $^{73}$

\section{Conclusion}

As the older population expands, technology applications have the potential to support aging in place for elderly, improving quality of life and reducing healthcare costs.

With advancing technology, sensors and robots may have the capabilities to support older adults in gait measures and mobility. The purpose of this article provides the state of the art of the area of robotic and sensor technologies that could be used for evaluation of the mobility and gait of an elder human. 
From our search, we identified 35 studies regarding sensors and robots that assist with some aspect of mobility and gait in elderly people.

A great number of sensor and robotic technologies exist and can be used for gait and mobility evaluation of an elder person at home in an automated way without the need of the physical presence of any medical personnel.

Eventually, the potential for these technologies to support dementia care at home can reduce healthcare expenditure secondary to formal care needs and premature institutional care. ${ }^{74}$

Comprehensive mobility assessments should include capacity measures as well as measures of real-life out-of-home mobility.

However, exploiting the potential for technology to meet care for elderly patients' needs depends on a number of factors, including raising awareness of available technologies and their utility, promoting accessibility and affordability, and overcoming challenges to acceptance and use.

Future research, rigorous clinical trials, and continuous sensor and robotic developments are required to improve the use of advanced technologies to be integrated with current care of aging.

\section{Acknowledgment}

The research leading to these results has received funding from the European Union Horizons 2020 - the Framework Programme for Research and Innovation (2014-2020) under grant agreement 643808 Project MARIO "Managing active and healthy aging with use of caring service robots."

\section{Author Disclosure Statement}

No competing financial interests exist.

\section{References}

1. Bergland A, Jørgensen L, Emaus N, Strand BH. Mobility as a predictor of all-cause mortality in older men and women: 11.8 year follow-up in the Troms $\emptyset$ study. BMC Health Serv Res 2017;17:22.

2. World Health Organization. World Report on Ageing and Health. 2015. Available at http://apps.who.int/iris/bitstream/ 10665/186463/1/9789240694811_eng.pdf (last accessed February 26,2016$)$.

3. Mänty M, Heinonen A, Leinonen R, Törmäkangas T, SakariRantala R, Hirvensalo M, et al. Construct and predictive validity of a self-reported measure of preclinical mobility limitation. Arch Phys Med Rehabil 2007;88:1108-1113.

4. Verghese J, Le Valley A, Hall CB, Katz MJ, Ambrose AF, Lipton RB. Epidemiology of gait disorders in communityresiding older adults. J Am Geriartr Soc 2006;54:255-261.

5. Mahlknecht P, Kiechl S, Bloem BR, Willeit J, Scherfler C, Gasperi A, et al. Prevalence and burden of gait disorders in elderly men and women aged 60-97 years: A populationbased study. PLoS One 2013;8:e69627.

6. Rosso AL, Studenski SA, Chen WG, Aiznstein HJ, Alexander NB, Bennet DA, et al. Aging, the central nervous system, and mobility. J Gerontol A Biol Sci Med Sci 2013; 68:1379-1386.

7. Guralnik JM, Fried LP, Salive ME. Disability as a public health outcome in the aging population. Annu Rev Public Health 1996;17:25-46.
8. Visser M, Goodpaster BH, Kritchevsky SB, Newman AB, Nevitt M, Rubin SM, et al. Muscle mass, muscle strength, and muscle fat infiltration as predictors of incident mobility limitations in well-functioning older persons. J Gerontol A Biol Sci Med Sci 2005;60:324-333.

9. Buchman AS, Wilson RS, Boyle PA, Tang Y, Fleischman DA, Bennett DA. Physical activity and leg strength predict decline in mobility performance in older persons. J Am Geriatr Soc 2007;55:1618-1623.

10. Wang C-Y, Yeh C-J, Hu M-H. Mobility-related performance tests to predict mobility disability at 2-year followup in community-dwelling older adults. Arch Gerontol Geriatr 2011;52:1-4.

11. Clark DO, Stump TE, Hui SL, Wolinsky FD. Predictors of mobility and basic ADL difficulty among adults aged 70 years and older. J Aging Health 1998;10:422-440.

12. Ayis S, Gooberman-Hill R, Bowling A, Ebrahim S. Predicting catastrophic decline in mobility among older people. Age Ageing 2006;35:382-387.

13. Ferrucci L, Bandinell S, Benvenuti E, Di Iorio A, Macchi C, Harris T, et al. Subsystems contributing to the decline in ability to walk: Bridging the gap between epidemiology and geriatric practice in the InCHIANTI study. Am Geriatr Soc 2000;48:1618-1625.

14. Cooper KM, Bilbrew D, Dubbert PM, Kerr K, Kirchner K. Health barriers to walking for exercise in elderly primary care. Geriatr Nurs 2001;22:258-262.

15. Studenski S. Bradypedia: Is gait speed ready for clinical use? J Nutr Health Aging 2009;13:878-880.

16. Buchner DM. One lap around the track: The standard for mobility disability? J Gerontol A Biol Sci Med Sci 2008; 63:586-587.

17. Chaudhry SI, McAvay G, Ning Y, Allore HG, Newman AB, Gill TM. Geriatric impairments and disability: The cardiovascular health study. J Am Geriatr Soc 2010;58:1686-1692.

18. Hardy SE, Kang Y, Studenski SA, Degenholtz HB. Ability to walk $1 / 4$ mile predicts subsequent disability, mortality, and health care costs. J Gen Intern Med 2011;26:130-135.

19. Gorgon E, Said C, Galea M. Mobility on discharge from an aged care unit. Physiother Res Int 2007;12:72-81.

20. Woolham J (ed): Assistive Technology in Dementia Care. London, United Kingdom: Hawker Publications Ltd., 2006, pp. 1-105.

21. Liberati A, Altman DG, Tetzlaff J, Mulrow C, Gotzsche PC, Ioannidis JP, Clarke M, Devereaux PJ, Kleijnen J, Moher D. The PRISMA statement for reporting systematic reviews and meta-analyses of studies that evaluate healthcare interventions: Explanation and elaboration. BMJ 2009; 339:b2700.

22. Snijders AH, van de Warrenburg BP, Gilali N, Bloem BR. Neurological gait disorders in elderly people: Clinical approach and classification. Lancet Neuro 2007;6:63-74.

23. Hannes K, Macaitis K. A move to more systematic and transparent approaches in qualitative evidence synthesis: Update on a review of published papers. Qual Res 2012; 12:402-442.

24. Barnett-Page E, Thomas J. Methods for the synthesis of qualitative research: A critical review. BMC Med Res Methodol 2009;9:59.

25. Grant MJ, Booth A. A typology of reviews: An analysis of 14 review types and associated methodologies. Health Info Libr J 2009;26:91-108.

26. Muro-de-la-Herran A, Garcia-Zapirain B, Mendez-Zorrilla A. Gait analysis methods: An overview of wearable and 
non-wearable systems, highlighting clinical applications. Sensors 2014;14:3363-3394.

27. Tao W, Liu T, Zheng R, Feng H. Gait analysis using wearable sensors. Sensors 2012;12:2255-2283.

28. Pratheepan Y, Condell JV, Prasad G. The use of dynamic and static characteristics of gait for individual identification. Proceedings of 13th International Machine Vision and Image Processing Conference 2009:111-116.

29. Geraedts HAE, Zijlstra W, Van Keeken HG, Zhang W, Stevens M. Validation and user evaluation of a sensorbased method for detecting mobility-related activities in older adults. PLoS One 2015;10:e0137668.

30. Zeng H, Zhao Y. Sensing movement: Microsensors for body motion measurement. Sensors (Basel) 2011;11:638660.

31. Ganea R, Paraschiv-lonescu A, Aminian K. Detection and classification of postural transitions in real-world conditions. IEEE Trans Neural Syst Rehabil Eng 2012;20:688696.

32. Wang R, Medioni G, Winstein CJ, Blanco C. Home monitoring musculo-skeletal disorders with a single $3 \mathrm{D}$ sensor. IEEE Conference on Computer Vision and Pattern Recognition Workshops 2013:521-528.

33. Cho CW, Chao WH, Lin SH, Chen YY. A vision-based analysis system for gait recognition in patients with Parkinson's disease. Expert Syst Appl 2009;36:7033-7039.

34. Kashani FB, Medioni G, Nguyen K, Nocera L, Shahabi C, Wang R, et al. Monitoring mobility disorders at home using $3 \mathrm{D}$ visual sensors and mobile sensors. Proceedings of the 4th Conference on Wireless Health 2014;9.

35. Kusakunniran W, Wu Q, Zhang J, Li H. Support vector regression for multi-view gait recognition based on local motion feature selection, computer vision and pattern recognition (CVPR). IEEE Conference 2010:974-981.

36. Broekens J, Heerink M, Rosendal H. Assistive social robots in elderly care: A review. Gerontechnology 2009;8:94-103.

37. Carpenter J, Davis JM, Erwin-Stewart N, Lee TR, Bransford JD, Vye N. Gender representation and humanoid robots designed for domestic use. Int J Soc Robot 2009;1: 261-265.

38. Duffy BR. Anthropomorphism and the social robot. Rob Auton Syst 2003;42:177-190.

39. Kamide H, Mae Y, Kawabe K, Shigemi S, Arai T. Effect of human attributes and type of robots on psychological evaluation of humanoids. IEEE Workshop Advanced Robotics and its Social Impacts 2012:40-45.

40. Kusuda Y. Toyota's violin-playing robot. Indus Rob 2008; 35:504-506.

41. Tapus A, Tapus C, Matarić M. Long term learning and online robot behavior adaptation for individuals with physical and cognitive impairments. In: Howard A, Iagnemma K, Kelly A (eds). Field and Service Robotics. BerlinHeidelberg, Germany: Springer, 2010, pp. 389-398.

42. Shamsuddin S, Yussof H, Ismail L, Hanapiah FA, Mohamed $\mathrm{S}$, Ali Piah $\mathrm{H}$, et al. Initial response of autistic children in human-robot interaction therapy with humanoid robot NAO. Proc Eng 2012;41:1533-1538.

43. López Recio D, Márquez Segura E, Márquez Segura L, Waern A. The NAO models for the elderly. Proceedings of the 8th ACM/IEEE International Conference on HumanRobot Interaction 2013:187-188.

44. Lera FJ, Rodríguez V, Rodríguez C, Matellán V. Augmented reality in robotic assistance for the elderly. In: Gonzalez IA (ed). International Technology Robotics Applications.
Cham, Switzerland: Springer International Publishing, 2014, pp. 3-11.

45. Esquenazi A, Talaty M, Jayaraman A. Powered exoskeletons for walking assistance in persons with central nervous system injuries: A narrative review. PM R 2017;9:46-62.

46. Galle S, Derave W, Bossuyt F, Calders P, Malcolm P, De Clercq D. Exoskeleton plantarflexion assistance for elderly. Gait Posture 2017;52:183-188.

47. Wilson M. An Exoskeleton for the Elderly. Posted December 20, 2016. Available at www.fastcodesign.com/3066728/anexoskeleton-for-the-elderly (last accessed March 29, 2017).

48. Wall A, Borg J, Palmcrantz S. Clinical application of the Hybrid Assistive Limb (HAL) for gait training-a systematic review. Front Syst Neurosci 2015;9.

49. Nilsson A, Vreede KS, Haglund V, Kawamoto H, Sankai Y, Borg J. Gait training early after stroke with a new exoskeleton-The hybrid assistive limb: A study of safety and feasibility. J Neuroeng Rehabil 2014;11:92.

50. Oh S, Hori Y. Human-Friendly motion control of powerassisted wheelchair. In: Mohammed S, Moreno JC, Kong $\mathrm{K}$, Amirat Y (eds). Intelligent Assistive Robots. Switzerland: Springer International Publishing, 2015, pp. 339-369.

51. Low KH. Recent development and trends of clinical-based gait rehabilitation robots. In: Mohammed S, Moreno JC, Kong K, Amirat Y (eds). Intelligent Assistive Robots. Switzerland: Springer International Publishing, 2015, pp. 41-75.

52. Xu W, Huang J, Wang Y, Tao C, Cheng L. Reinforcement learning-based shared control for walking-aid robot and its experimental verification. Adv Robot 2015;29:1463-1481.

53. International Federation of Robotics. Definition of Service Robots. 2014. Available at www.ifr.org/service-robots/ statistics (last accessed November 3, 2017).

54. Dautenhahn K, Nehaniv CL, Walters ML, Robins B, KoseBagci H, Mirza NA, et al. KASPAR-A minimally expressive humanoid robot for human-Robot interaction research. Appl Bionics Biomech 2009;6:369-397.

55. Yamazaki K, Ueda R, Nozawa S, Kojima M, Okada K, Matsumoto K, et al. Home-assistant robot for an aging society. Proceedings of the IEEE 2012;100:2429-2441.

56. Compute Scotland. Robots:Open Source and for the Elderly. Available at www.computescotland.com/robotsopensource-and-for-the-elderly-4849.php (last accessed March 4, 2017).

57. Cavallo F, Aquilano M, Bonaccorsi M, Limosani R, Manzi A, Carrozza MC, et al. Improving domiciliary robotic services by integrating the ASTRO robot in an AmI Infrastructure. In: Gearing Up and Accelerating Crossfertilization Between Academic and Industrial Robotics Research in Europe, Volume 94 of the Series Springer Tracts in Advanced Robotics, 2014, pp. 267-282.

58. Graf B, Reiser U, Hagele M, Mauz K, Klein P. Robotic home assistant Care-O-bot ${ }^{\circledR}$ 3-product vision and innovation platform. In: Advanced Robotics and its Social Impacts (ARSO), IEEE Workshop 2009:139-144.

59. Robotics Today. Enon. Available at www.roboticstoday. com/robots/enon (last accessed March 4, 2017).

60. Rosofsky I. The Robots Have Dawned: Meet the Carebot. Robots Replacing Humans for the Frail and Elderly. Psychology Today. Posted June 28, 2009. https://www .psychologytoday.com/blog/adventures-in-old-age/200906/ the-robots-have-dawned-meet-the-carebot (last accessed March 4, 2017).

61. Kalogianni A. Toyota Develops Human Support Robot for Elder Care. Posted July 16, 2015. Available at www 
.digitaltrends.com/cars/toyota-develops-human-support-robotfor-elder-care (last accessed March 4, 2017).

62. Ferro F, Marchionni L. REEM: A humanoid service robot. In: Armada MA, Sanfeliu A, Ferre M (eds). ROBOT2013: First Iberian Robotics Conference. Cham, Switzerland: Springer International Publishing, 2014, pp. 521-525.

63. Garcia D, Tran A. The PR2: A Service Robot. Created April 27, 2013. Available at https://prezi.com/mnqvh2 kk3tm/the-pr2-a-service-robot (last accessed March 4, 2017).

64. Technovelgy.com. SmartPal V Mecha-Gumby Service Robot. Available at www.technovelgy.com/ct/ScienceFiction-News.asp?NewsNum=1331 (last accessed March 4, 2017).

65. Quick D. Twendy-One Ready to Lend a Robotic Helping Hand to the Elderly. Posted March 12, 2010. Available at http://newatlas.com/twendy-one-robot-elderly/14496 (last accessed March 4, 2017).

66. Neto AF, Elias A, Cifuentes C, Rodriguez C, Bastos T, Carelli R. Smart walkers: Advanced robotic human walking-aid systems. In: Mohammed S, Moreno JC, Kong $\mathrm{K}$, Amirat Y (eds). Intelligent Assistive Robots. Switzerland: Springer International Publishing, 2015, pp. 103-131.

67. Clotet E, Martínez D, Moreno J, Tresanchez M, Palacín J. Assistant personal robot (APR): Conception and application of a tele-operated assisted living robot. Sensors (Basel) 2016;16:610.

68. Shibata T. Theraputic seal robot as biofeedback medical device: Qualitative and quantitative evaluations of robot therapy in dementia care. Proceedings of the IEEE 2012; 100:2527-2538.

69. Dimas J, Leite J, Pereira A, Cuba P, Prada R, Paiva A. Pervasive pleo: Long-term attachment with artificial pets. In: Please enjoy!: Workshop on playful experiences in Mobile HCI, 2010.

70. Robarts S. Buddy Robot Wants to Be a Companion for Your Family. Posted July 8, 2015. Available at http:// newatlas.com/buddy-family-companion-robot/38360 (last accessed March 4, 2017).

71. Cheng HZ. NEC Releases PaPeRo Petit Robot to Take Care of the Elderly. Posted November 13, 2013. Available at www.thetechrevolutionist.com/2013/11/nec-releasespapero-petit-robot-to-take.html (last accessed March 4, 2017).

72. Leite I, Martinho C, Pereira A, Paiva A. iCat: An affective game buddy based on anticipatory mechanisms. Proceedings of the 7th International Joint Conference on Autonomous Agents and Multiagent Systems, Volume 3. Richland, USA: International Foundation for Autonomous Agents and Multiagent Systems, 2008, pp. 1229-1232.

73. Wada K, Shibata T. Living with seal robots-Its sociopsychological and physiological influences on the elderly at a care house. Robotics, IEEE Transactions 2007;23:972-980.

74. Bossen AL, Kim H, Williams KN, Steinhoff AE, Strieker M. Emerging roles for telemedicine and smart technologies in dementia care. Smart Homecare Technol Telehealth 2015;3:49-57.

Address correspondence to: Grazia D'Onofrio

Complex Unit of Geriatrics Department of Medical Sciences IRCCS "Casa Sollievo della Sofferenza" Viale Cappuccini 1 San Giovanni Rotondo 71013 Foggia Italy

E-mail: graziadonofrio@libero.it; g.donofrio@operapadrepio.it

Received: March 31, 2017 Accepted: May 8, 2017 